\title{
Conditional discrimination in Octopus vulgaris
}

\author{
Koji Tokuda $\cdot$ Reiji Masuda $\cdot$ Yoh Yamashita
}

Received: 16 February 2014/ Accepted: 10 November 2014/Published online: 26 November 2014

(C) Japan Ethological Society and Springer Japan 2014

\begin{abstract}
Conditional discrimination in the octopus (Octopus vulgaris) was studied using successive discrimination training. The experimental animals were divided into two groups, and a barrel-shaped white object (stimulus) was presented to each group. One of the groups was rewarded with food for responding to the stimulus, but only when the tank was aerated, whereas the other group was rewarded with food for responding to the stimulus when the aeration was switched off. The number of trials in which octopuses responded to the stimulus, and the latency of the responses, were significantly different between trials with the aeration on and trials with the aeration off, in both groups. Therefore, the octopuses learned to conditionally discriminate.
\end{abstract}

Keywords Invertebrate - Cephalopod · Mollusk ·

Learning $\cdot$ Successive discrimination

\section{Introduction}

Conditional discrimination is a form of discrimination in which the appropriate response depends on the environment (i.e., context). Conditional discrimination has been widely used to examine learning, memory, perception, and other psychological aspects of behavior in humans and

K. Tokuda $(\bowtie) \cdot$ R. Masuda $\cdot$ Y. Yamashita

Maizuru Fisheries Research Station, Field Science Education and Research Center, Kyoto University, Nagahama, Maizuru, Kyoto 625-0086, Japan

e-mail: pallas-athena@asahinet.jp

Present Address:

K. Tokuda

Suehiro 3-10-22-\#5, Miki, Hyogo 673-0403, Japan other animals. Animals such as chimpanzees, Japanese macaques, rabbits, rats, pigeons, and goldfish can conditionally discriminate (Brown et al. 2005; Castro and Wasserman 2010; Fujita 1983; Martinez and Matsuzawa 2009; Myers et al. 2000; Rogers and Steinmetz 1998; Zerbolio 1984).

Octopuses have particularly large and elaborate brains, and sophisticated learning capability among invertebrates (Grasso and Basil 2009; Hanlon and Messenger 1996). They live in many types of habitat, and it would be expected that behaving differently under different circumstances would confer an adaptive advantage to them; For example, the common octopus, Octopus vulgaris, inhabits a variety of habitats, including rocky, sandy or muddy substrates, coral reefs, and sea-grass beds, from the surface to depth of more than $200 \mathrm{~m}$ (Katsanevakis and Verriopoulos 2004), and exhibits different behaviors according to substrate type and situation (Hanlon and Messenger 1996). It would be expected, therefore, that conditional discrimination (where animals make appropriate responses that correspond to the environment) would be important for such animals.

There have been two papers published that have related conditional discrimination to the behavior of octopuses. In an experimental study, Hvorecny et al. (2007) found that Octopus bimaculoides exhibits conditional discrimination. In their experiment, two experimental tanks were used for each experimental animal, both tanks equipped with several landmarks. The tanks also contained a burrow that functioned as an escape, and a false escape on the opposite side at the bottom of the tanks. The landmarks were unique to each tank. An octopus was placed in a brightly lit experimental tank and allowed to explore, and enter the escape burrow avoiding the light, so that the animal would learn to find the real escape before finding the false one. 
Five trials were alternately conducted in each of the two experimental tanks. Because some of the octopuses were successful, Hvorecny et al. (2007) concluded that octopuses could conditionally discriminate. However, in that experimental setting, it is possible that the octopuses just learned the location of the escape using landmarks, or learned the different appearances of the real and false escapes without conditionally discriminating between them. Huffard et al. (2010) investigated the aggressive behavior of Abdopus aculeatus and found that this species changed mating tactics depending on the circumstances, and suggested that this may have been due to conditional discrimination. However, conditional discrimination has not been conclusively shown to be exhibited by octopuses.

The present study tested the hypothesis that $O$. vulgaris can conditionally discriminate. The capability of the octopus was evaluated in successive discrimination training, which involves the presentation of only one of the discriminative stimuli in each trial (Lipsitt 1961).

\section{Materials and methods}

\section{Materials}

Eleven $O$. vulgaris captured in Maizuru Bay, Kyoto Prefecture, Japan $\left(135^{\circ} 3^{\prime}-135^{\circ} 4^{\prime} \mathrm{E}, 35^{\circ} 5^{\prime}-135^{\circ} 3^{\prime} \mathrm{N}\right)$ were used. They weighed $268-1899 \mathrm{~g}$ at the end of the experiment. The experiment was conducted between 19 October 2009 and 30 January 2010. On experimental days, the octopuses were not given any food except thawed shrimp as a reward for the training. On nonexperimental days, they were mainly fed thawed clams.

\section{Apparatus}

The octopuses were kept individually in separate black circular tanks (97.5 $\mathrm{cm}$ in diameter and $77.0 \mathrm{~cm}$ in depth), and the experiment was conducted in the same tanks, because movement between tanks may have caused sufficient stress to interfere with their performance in the tests. The water was $35-40 \mathrm{~cm}$ deep. Filtered sea water was continuously supplied to, and drained from, the tanks. The bottoms of the tanks were covered with small stones (with diameters that ranged from 1 to $5 \mathrm{~cm}$ ), and seven air stones and a den made of bricks and concrete blocks were placed at the rim of the bottom, dividing the perimeter into eight equal sections (Fig. 1). The aeration was always simultaneously switched on or off, in all the stones. A 10-30-cmwide white plastic net ( $\sim 15$-mm mesh size) was set facing inward along the rims of the tanks, to keep the octopuses from escaping.

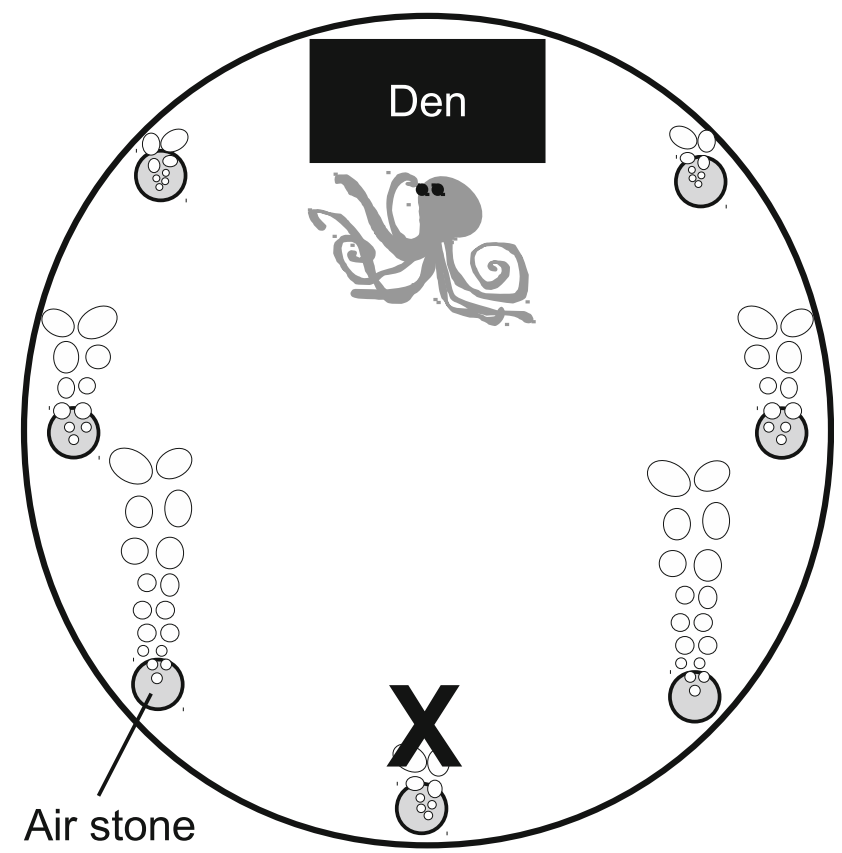

Fig. 1 Schematic diagram of the experimental tank viewed from above. The den and the seven air stones were fixed at the rim of the bottom, dividing the perimeter into eight equal sections. $X$ represents where the stimulus was presented during preliminary training 2 and conditional discrimination training. Figure produced using LibreOffice 4.1.3.2 Draw

A barrel-shaped ceramic stone (Tanaka Sanjiro Shoten, Fukuoka, Japan) was presented to the octopuses for the discrimination trainings as a stimulus. It measured 5-6 cm in length and was $4 \mathrm{~cm}$ wide, and was covered with white vinyl tape to make it conspicuous against the black wall of the tanks. It was equipped with a hook made of a single strand of wire on the side, on which to place a cut shrimp. The stimulus was attached to the end of a polyvinyl chloride (PVC) pipe covered with black vinyl tape. The pipe was $1.8 \mathrm{~cm}$ in diameter and $135 \mathrm{~cm}$ in length. The stimulus was manually presented to the octopuses.

\section{General procedure}

The experiment consisted of three phases: preliminary training 1 , preliminary training 2 , and conditional discrimination training (Fig. 2). Ten trials were conducted per experimental day for each phase. Trials were conducted between 08:50 and 09:20, 09:30 and 10:00, 10:10 and 10:40, 10:50 and 11:20, 11:30 and 12:00, 13:30 and 14:00, $14: 10$ and 14:40, 14:50 and 15:20, 15:30 and 16:00, and 16:10 and 16:40. The octopuses were divided into aeration + and aeration - groups, which included six and five individuals, respectively. The aeration + octopuses were only rewarded for touching the stimulus when the aeration 


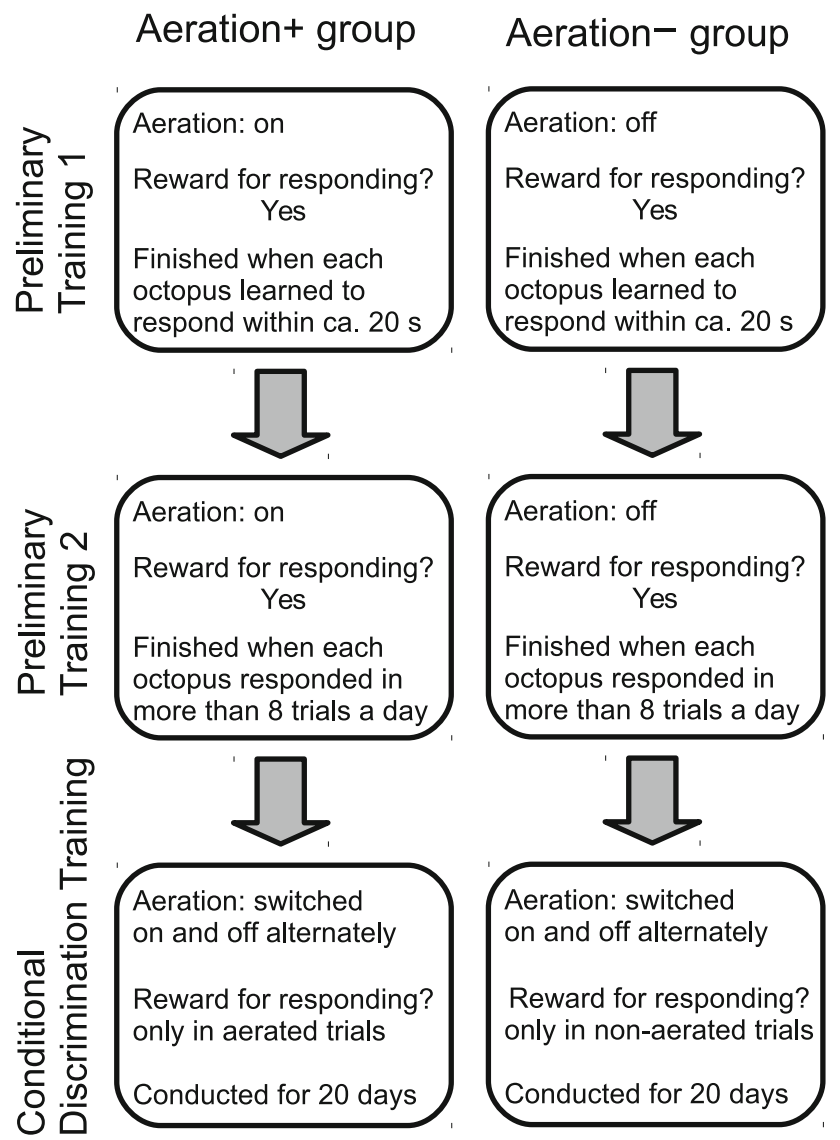

Fig. 2 Flowchart showing the experimental procedure. Figure produced using LibreOffice 4.2.3.3 Draw

was switched on, whereas the aeration- octopuses were only rewarded when the aeration was switched off.

\section{Preliminary training 1}

The aim of this phase was that each animal would learn to touch the stimulus. The aeration was kept on in the aeration + tanks and off in the aeration - tanks, during all of the trials. After all trials had finished on each experimental day, the aeration was alternately kept on or off until the next experimental day. The aeration was switched on or off 10-20 min before the first trial. During each trial, the stimulus, with a cut shrimp attached, was presented to the focal octopus; the size of the shrimp used was dependent upon the size of the focal octopus. The focal octopus was allowed to take the shrimp as a reward if it touched the stimulus. Initially, it was at the experimenter's discretion regarding how, and for how long, to present the stimulus.

During the early trials, the experimenter presented the shrimp on the visible side of the stimulus, in order to attract the octopus's attention. Once a focal octopus got used to this procedure, the stimulus was slowly placed on the bottom, along the wall facing the den. The stimulus was placed approximately $10 \mathrm{~cm}$ from the wall, so that it would not be covered in bubbles from nearby air stones. Once an octopus had learned to touch the stimulus within approximately $20 \mathrm{~s}$ of it being presented, preliminary training 1 was terminated and preliminary training 2 started on the next experimental day.

\section{Preliminary training 2}

The aim of this phase was that the octopuses would learn to respond to (touch) the stimulus within $30 \mathrm{~s}$ of it being presented to them. The aeration was set as it was during preliminary training 1 . During each trial, the stimulus was slowly placed on the bottom, along the wall facing the den. Each trial started when any part of the octopus's body was in contact with the den. The stimulus was placed approximately $10 \mathrm{~cm}$ from the wall, and a cut shrimp was attached to the nonvisible side of the stimulus to the octopus. When an octopus touched the stimulus, it was able to feel the cut shrimp and take it as a reward. If an octopus touched the stimulus within $30 \mathrm{~s}$ of it being presented, the trial was considered to be a success. If not, the stimulus was removed from the tank and the trial was terminated. If more than eight trials were successful in one day, this phase was terminated and conditional discrimination training started on the next experimental day.

\section{Conditional discrimination training}

During this phase, we examined whether the octopuses were capable of conditional discrimination. The training was conducted over 20 days for each octopus, and 10 trials were conducted each day. The aeration was alternately set on or off during each trial, switched on or off more than 10 min before the trials. At the end of each experimental day, the aeration was kept as it was set for the last trial of the day, until the first trial of the next experimental day had finished. During each trial, the stimulus was presented to the animals in the same manner as in preliminary training 2 . In the aeration + treatment, the cut shrimp was only attached to the nonvisible side of the stimulus during aerated trials. If the octopus touched the stimulus within $30 \mathrm{~s}$ of it being presented during an aerated trial, they were allowed to take the shrimp as a reward. In the aerationtreatment, the cut shrimp was only attached to the nonvisible side of the stimulus during nonaerated trials, and the animals were allowed to take the shrimp if they touched the stimulus within $30 \mathrm{~s}$ of it being presented. Under the opposite circumstances (i.e., an aerated trial with an individual from the aeration - group, or a nonaerated trial with an individual from the aeration + group), if an octopus touched the stimulus, it was quickly removed from the tank before the octopus could take the cut shrimp, and the trial 
was terminated. In all the trials, if an octopus did not touch the stimulus within $30 \mathrm{~s}$, it was also removed from the tank. The responses and the response latency (the duration of time it took for an octopus to touch the stimulus after it was presented) were recorded.

The number of trials in which the octopuses responded to the stimulus, and the response latency, were compared between aerated and nonaerated trials for both group using Fisher's exact test and log-rank test, respectively. We did not record the result of the eighth trial on the 18th day for one aeration- octopus, and therefore lack data for one aerated trial. All the statistical analyses were conducted using R version 3.0.2 (R Core Team 2013).

\section{Results}

Preliminary training 1 and 2 required 1-15 days (median 1 day) and 1-9 days (median 1 day), respectively. Over the entire period of conditional discrimination training, the aeration+ group responded significantly more to the stimulus in aerated trials than it did in nonaerated trials, and the aeration - group responded significantly more in nonaerated trials (Fisher's exact test, $p<0.01$; Fig. 3). To evaluate the learning progress, we conducted an analysis of the daily number of responding trials. There were no significant differences on any day in the aeration+ group, whereas there were significant differences on the 6th, 12th, 16 th, and 20th days in the aeration - group (Fisher's exact test, $p<0.05)$.

Over the entire period, the aeration + group exhibited a shorter response latency during aerated trials than during nonaerated trials, and the aeration- group exhibited a shorter response latency during nonaerated trials than during aerated trials (log-rank test, $p<0.01$; Fig. 4). The analysis of daily response latency showed that the aeration + group exhibited a shorter latency in aerated trials on the 20th day (log-rank test, $p<0.05$ ). The aeration - group exhibited a shorter latency in nonaerated trials on the 6th, 8 th, 12th to 18 th, and 20th days (log-rank test, $p<0.05$ ).

\section{Discussion}

We found that octopuses do exhibit conditional discrimination. Animals in the aeration+ group responded more, and had a shorter latency period, when the aeration was on, whereas those in the aeration- group exhibited the opposite trend. However, analyses of daily differences revealed a less clear response than we had anticipated, suggesting that the conditional discrimination training was only partially successful. It is possible that, because the octopuses were not disadvantaged if they responded to the stimulus

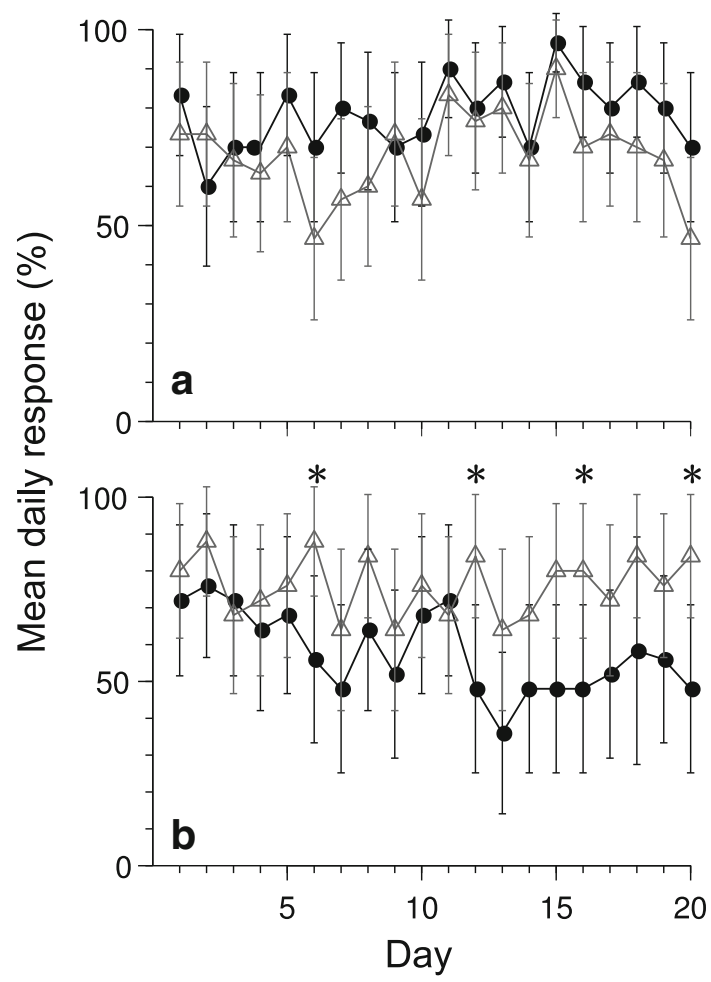

Fig. 3 Mean daily percentage of responses by the octopuses averaged per day: a aeration + group, b aeration- group. Filled circles and open triangles represent aerated and nonaerated trials, respectively. Evaluated over the entire training period, both groups exhibited a significant difference between aerated and nonaerated trials (Fisher's exact test, $p<0.01)$. Evaluated on daily basis, significant differences were found on days with asterisks (Fisher's exact test, $p<0.05$ ). There were no significant differences on any day in the aeration+ group. Error bars indicate standard error (SE). Figure produced using R 3.0.2 and LibreOffice 4.1.3.2 Draw

during an inappropriate trial (they were given a reward every time they responded), they responded in inappropriate trials and therefore we underestimated their learning ability. Alternatively, because conditional discrimination is a difficult task, the correct response may not always be given, or the animals might need further trials to learn properly. Messenger and Sanders (1972) reported that fewer cues for discrimination reduced the correct responses of octopuses trained to distinguish a pair of shapes. Sanders (1975) reviewed studies in which the discrimination performance of octopuses changed according to the combination of objects discriminated between. They showed that the difficulty of discrimination tasks affects learning performance in octopuses. Kuba et al. (2006) reported that, when $O$. vulgaris was repeatedly presented with identical stimuli over days, the latency of response to the stimuli did not change, although they exhibited learning in other aspects. This suggests that a response latency may not reflect octopus's learning clearly and may be a cause of unclear differences in latencies between aerated and nonaerated trials in the present study. 


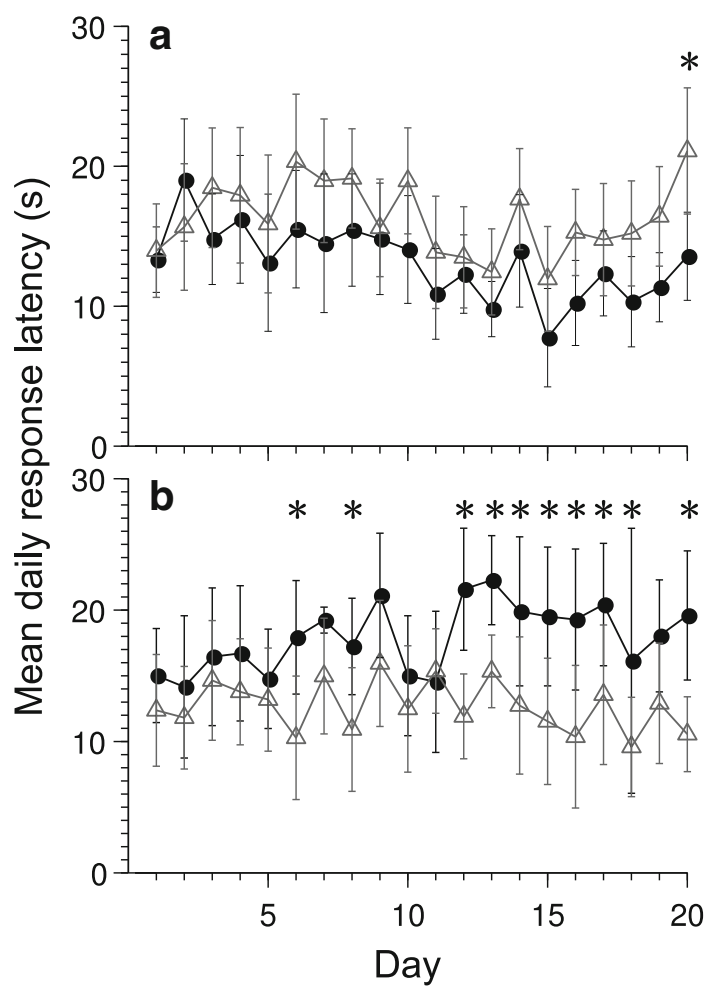

Fig. 4 Mean daily response latencies of the octopuses averaged per day: a aeration + group, b aeration- group. Filled circles and open triangles represent aerated and nonaerated trials, respectively. For presentational purposes, cases in which an octopus did not respond were treated as a response after $30 \mathrm{~s}$; however, these time-outs were taken into account when the data were statistically analyzed. Evaluated over the entire training period, both groups exhibited a significant difference between the aerated and nonaerated trials (logrank test, $p<0.01$ ). Evaluated on a daily basis (every five trials), significant differences were found on days with asterisks (log-rank test, $p<0.05)$. Error bars indicate standard error (SE). Figure produced using R 3.0.2 and LibreOffice 4.1.3.2 Draw

The aeration - group exhibited more obvious responses than did the aeration+ group. This was possibly because the aeration + group was distracted from the stimulus under aerated conditions, by bubbles and noise emitted by the aerators. The aerators were so conspicuous that the animals often reached for the air stones when the aeration was turned on.

It is possible that the octopuses could have smelled the shrimp attached to the stimulus when it was presented to them. Wells et al. (1965) reported that octopuses can sense chemicals dissolved in water. However, we assumed that the animals did not discriminate the stimulus using chemical cues, because they seemed to be unable to detect a cut shrimp without actually touching it. Indeed, many times we observed $O$. vulgaris touching an object with a cut shrimp attached to it, but missing the shrimp by a few centimeters or even shorter distances and going back to its den (Tokuda unpublished data). Therefore, we are of the opinion that in the present study the octopuses identified the stimulus using visual cues.

Conditional discrimination is considered a higher form of learning and is associated with vertebrates (Thomas 1980, 1996; Zuckerman and Blough 1974); however, some invertebrates, including the honeybee Apis mellifera (Couvillon and Bitterman, 1988), the opisthobranch mollusk Aplysia californica (Colwill et al. 1988), the pharaoh cuttlefish Sepia pharaonis, and the common cuttlefish S. officinalis (Hvorecny et al. 2007), do possess this ability. The present study adds another species to this list. It is reasonable to assume that octopuses are capable of conditional discrimination, considering that two cuttlefishes, $S$. officinalis and $S$. pharaonis, which are closely related to octopuses, and the opisthobranch mollusk Aplysia californica, which belongs to the same phylum as octopuses and has a simpler nervous system, can conditionally discriminate (Colwill et al. 1988; Hvorecny et al. 2007). It is therefore possible that coleoids (or possibly cephalopods) are generally able to conditionally discriminate. It would be informative to study conditional discrimination in other mollusks. Although there have been many studies on conditional discrimination in animals (Thomas 1996), most of them have investigated vertebrates. We hope that conditional discrimination in invertebrates will be studied more widely, in order to gain a better general understanding of learning in animals.

Acknowledgments We thank the anonymous reviewers whose comments substantially improved the quality of the manuscript.

\section{References}

Brown KL, Pagani JH, Stanton ME (2005) Spatial conditional discrimination learning in developing rats. Dev Psychobiol 46:97-110

Castro L, Wasserman EA (2010) Effects of stimulus size and spatial organization on pigeons' conditional same-different discrimination. Behav Process 83:162-171

Colwill RM, Absher RA, Roberts ML (1988) Conditional discrimination learning in Aplysia californica. J Neurosci 8:4440-4444

Couvillon PA, Bitterman ME (1988) Compound-component and conditional discrimination of colors and odors by honeybees: further tests of a continuity model. Anim Learn Behav 16:67-74

Fujita K (1983) Acquisition and transfer of a higher-order conditional discrimination performance in the Japanese monkey. Jpn Psychol Res 25:1-8

Grasso FW, Basil JA (2009) The evolution of flexible behavioral repertoires in cephalopod molluscs. Brain Behav Evol 74:231-245

Hanlon RT, Messenger JB (1996) Cephalopod behaviour. Cambridge University Press, Cambridge

Huffard CL, Caldwell RL, Boneka F (2010) Male-male and malefemale aggression may influence mating associations in wild octopuses (Abdopus aculeatus). J Comp Psychol 124:38-46

Hvorecny LM, Grudowski JL, Blakeslee CJ, Simmons TL, Roy PR, Brooks JA, Hanner RM, Beigel ME, Karson MA, Nichols RH, 
Holm JB, Boal JG (2007) Octopuses (Octopus bimaculoides) and cuttlefishes (Sepia pharaonis, S. officinalis) can conditionally discriminate. Anim Cogn 10:449-459

Katsanevakis S, Verriopoulos G (2004) Abundance of Octopus vulgaris on soft sediment. Sci Mar 68:553-560

Kuba MJ, Byrne RA, Meisel DV, Mather JA (2006) Exploration and habituation in intact free moving Octopus vulgaris. Int J Comp Psychol 19:426-438

Lipsitt LP (1961) Simultaneous and successive discrimination learning in children. Child Dev 32:337-347

Martinez L, Matsuzawa T (2009) Visual and auditory conditional position discrimination in chimpanzees (Pan troglodytes). Behav Process 82:90-94

Messenger JB, Sanders GD (1972) Visual preference and two-cue discrimination learning in octopus. Anim Behav 20:580-585

Myers CE, Hopkins RO, Kesner RP, Monti L, Gluck MA (2000) Conditional spatial discrimination in humans with hypoxic brain injury. Psychobiology 28:275-282

R Core Team (2013) R: A language and environment for statistical computing. R Foundation for Statistical Computing, Vienna. http://www.R-project.org/
Rogers RF, Steinmetz JE (1998) Contextually based conditional discrimination of the rabbit eyeblink response. Neurobiol Learn Mem 69:307-319

Sanders GD (1975) The cephalopods. In: Corning WC, Dyal JA, Willows AOD (eds) Invertebrate learning, vol 3: cephalopods and echinoderms. Plenum, New York, pp 1-145

Thomas RK (1980) Evolution of intelligence: an approach to its assessment. Brain Behav Evol 17:454-472

Thomas RK (1996) Investigating cognitive abilities in animals: unrealized potential. Cognit Brain Res 3:157-166

Wells MJ, Freeman NH, Ashburner M (1965) Some experiments on the chemotactile sense of octopuses. J Exp Biol 43:553-563

Zerbolio DJ (1984) Acquisition, extinction, and reacquisition of a conditional discrimination to avoid shock by goldfish. Anim Learn Behav 12:163-170

Zuckerman DC, Blough DS (1974) Conditional discrimination in the goldfish. Anim Learn Behav 2:215-217 